\title{
Lipid-derived flavor and off-flavor of traditional and functional foods: an overview
}

\author{
Fereidoon Shahidi* and Won Young Oh
}

\begin{abstract}
Department of Biochemistry, Memorial University of Newfoundland, St. John's, NL, AlB 3X9, Canada
${ }^{*}$ Corresponding author: Fereidoon Shahidi, Department of Biochemistry, Memorial University of Newfoundland, St. John's, NL, AlB 3X9, Canada. Tel: +1 709864 8552; E-mail: fshahidi@mun.ca
\end{abstract}

DOI: $10.31665 /$ JFB.2020.10224

Received: April 09, 2020; Revised received \& accepted: June 20, 2020

Citation: Shahidi, F., and Oh, W.Y. (2020). Lipid-derived flavor and off-flavor of traditional and functional foods: an overview. J. Food Bioact. 10: 20-31.

\begin{abstract}
Flavor is an important aspect of both traditional as well as functional food acceptability and can be favorable or unfavorable depending on the chemical nature of the volatile compounds present, their potency, and the presence of non-volatile components. Lipid, as a major food component, contributes to the food flavor formation via both interactions with other components and/or due to its own degradation during food processing, cooking, and storage. This is particularly important when dealing with functional foods that may contain a high proportion of highly unsaturated oils. Lipid may be involved in the Strecker degradation and Maillard reaction, which occurs during food processing, and as a result, it forms a myriad of volatile compounds. Lipoxygenases and autoxidation of unsaturated fatty acids also play an important role in the development of volatile compounds as well as the storage conditions of oils under display lights in the supermarkets, if kept in clear bottles. In this contribution, a cursory account of the role of lipids in flavor formation is provided.
\end{abstract}

Keywords: Maillard reaction; Volatiles and non-volatiles; Lipid fatty acids; Oxidation; Flavor and off-flavor.

\section{Introduction}

Flavor is an important sensory aspect of the overall acceptability of food. While aroma volatiles have a major influence on flavor, taste properties of high-molecular-weight components and contribution from non-volatile precursors should also be considered. In addition, the effects of color, texture, juiciness, mouthfeel and temperature are among other factors that influence the overall sensory character of foods. In this case, special attention must be paid to functional and fortified foods in which flavor of such products should resemble those of their traditional counterparts.

The raw products often have little aroma and only a mild taste, but they serve as a rich reservoir of compounds with taste tactile properties as well as aroma precursors and possibly flavor enhancers. Upon processing, food develops its specific aroma. For example, coffee upon roasting produces a myriad of volatile compounds that are responsible for the desirable flavor attributed to coffee. In addition, meat upon heat processing, whether cooking, roasting, grilling or frying, produces specific meaty flavor that is dictated by the meat source such as species, breed, and feed as well as other variables (Yanagimoto et al., 2002; Yang et al., 2016). Apart from heating, fermentation plays a crucial role in the flavor development of many food and beverages (e.g. beer and wine) (Styger et al., 2011; Lee et al., 2015; Pan et al., 2014; Heitmann et al., 2017).

In general, the flavor of fats and oils as well as lipid-containing foods is also influenced by their constituents which may be undesirable, such as those produced upon autoxidation of unsaturated fatty acids or be desirable as in the case of most lipoxygenasederived lipid-based volatiles (Ho and Chen, 1994). In addition, the non-volatile taste-active constituents of muscle foods, including red meat, poultry, and seafood, contain free amino acids, reducing sugars, vitamins and nucleotide, among others (Shahidi, 1989; Shahidi, 2002). The interaction of these components with one another and/or their degradation products via the Strecker degradation and Maillard reaction produces a large number of intermediates and/or volatiles which contribute to the overall desirable aroma of such 
foods upon thermal processing and heating experienced during cooking, frying and grilling (Perez-Locas and Yaylayan, 2010). Lipids also serve as important contributor to the overall flavor of meat and seafoods and are responsible, at least in part, for distinct species-dependent aroma character and taste of muscle food. Of course, dietary regimes also influence the flavor of red meat, poultry and seafood products. In terms of plant oils, depending on their origin such as oilseeds, fruit oils and fruit seed oils, their fatty acid composition, triacylglycerol profile and presence of minor components, including bioactives, and storage conditions dictate their flavor and oxidative stability (Shahidi and Zhong, 2010; Chen et al., 2011; Li et al., 2016).

\section{Inter-relationship of aroma and Maillard reaction}

Maillard (1912) described the formation of brown pigments, named "melanoidins", when a reducing sugar was heated with an amino acid. He published 8 papers in the period of 1912-1916 on this topic. Maillard reaction is important in the development of color and flavor in foodstuffs, including those of roasted coffee and heat-processed meats, among others. Maillard reaction is responsible for the formation of a large array of chemical compounds belonging to furan, thiazole, oxazole, thiophene, pyrrole, pyridine and pyrazine products, among others. However, the importance of Maillard reaction was not recognized until 1950's.

Hodge (1953) was first to provide the basis for understanding the mechanisms involved in the early stages of Maillard reaction. The initial stages of Maillard reaction involved interaction of reducing sugars and carbonyl compounds with amino compounds to afford glycosylamines that were rearranged and dehydrated to various products such as furfurals and furanone derivatives, hydroxyketones and dicarbonyl compounds. Subsequent stages of Maillard reaction involved the interaction of these compounds with amines, amino acids, aldehydes, hydrogen sulfide and ammonia which eventually led to the formation of the characteristic aroma compounds of cooked meats. The desirable meaty aroma of cooked meats is influenced by sulfur-containing compounds (Mottram, 1998). Such sulfur compounds may be formed from the reaction of ribose and cysteine, among others. Thus, furan-3-thiol and thiophan-3-thiol and their derivatives are among desirable meaty aromas and bis-(2-methyl-3-furanyl) disulfide with an odor threshold of $0.02 \mathrm{ng} / \mathrm{kg}$ is known to possess a strong meat-like aroma. The content of some of the thiols found in boiled meats was summarized by Kerscher and Grosch (1998).

\section{Lipid Degradation and their Interaction with the Maillard reaction products}

Autooxidation of lipids leads to the formation of many volatile compounds that are often associated with the undesirable flavor and off-flavor development in cooked meats. The oxidative breakdown of the unsaturated portion of lipids involves a free radical chain reaction which proceeds via the formation of hydroperoxides (Choe and Min, 2006; McClements and Decker, 2007). Hydroperoxides do not have any of their own flavor but are unstable species. Thus, their subsequent decomposition produces carbonyl compounds, alcohols, ketones, furans, epoxy compounds and hydrocarbons, among others (Shahidi, 2002; Shahidi and Zhong, 2015). Some of these lipid degradation products possess off-flavor notes but some of them, such as hydrocarbons, have little influence on the overall flavor of cooked or thermally processed meat because of their relatively high threshold values (Shahidi, 2002). However, low threshold compounds such as aldehydes, unsaturated alcohols, ketones and lactones are thought to be important in meat aroma. Meanwhile, 2-pentylfuran, a heterocyclic compound, may be formed directly from the oxidation of linoleic acid (Fig. 1) and this compound is identified in cooked pork. 2-pentylfuran is known to be responsible for an off-flavor note, also known as reversion flavor (Ho et al., 1978). The probable mechanism for its formation is via cleavage of 9-hydroxyl radical of linoleic acid. The product, a conjugated diene radical, interacts with oxygen and forms a vinyl hydroperoxide. The vinyl hydroperoxide releases a hydroxyl radical and subsequently becomes alkoxyl radical. This then cyclizes and forms 2-pentylfuran.

The thermal degradation products of lipids, mainly aldehydes and ketones, serve as important reactive intermediates in the Maillard reaction. Mottram and co-workers (Mottram and Edwards, 1983; Whitfield et al., 1988; Farmer et al., 1989; Mottram, 1994) found that involvement of phospholipids in Maillard reaction led to the formation of 2-alkyl heterocyclic compounds and proposed that they were formed from the reaction of alkadienals, such as 2,4-decadienal, derived from oxidation of lipids, with $\mathrm{H}_{2} \mathrm{~S}$ and $\mathrm{NH}_{3}$. Thus, interaction of decadienal with $\mathrm{H}_{2} \mathrm{~S}$ and $\mathrm{NH}_{3}$ afforded 2-pentylpyridine, 2-hexylthiophene and 2-pentyl (2H)-thiapyran. Lipid-derived heterocyclic compounds found in beef and lamb included 2-alkylthiazoles, 2-alkyl-3-thiazolines, 2-alkyl(2H)-thiapyrans and 2-alkylthiophenes. The formation mechanisms of formation of these heterocyclic components are provided in Figure 2. Mottram and co-workers (Mottram and Edwards, 1983; Whitfield et al., 1988; Farmer et al., 1989; Farmer and Mottram, 1990) followed the reaction of cysteine with ribose under three different conditions. These were in the absence of lipids, with beef triacylglycerols (BTAG) or with beef phospholipids (BPL). The reaction afforded different levels of selected volatiles, as shown in Figure 3. In this, there was somewhat higher level of mercaptopentane, furan, and thiophenethiol when BTAG was present compared to BPL; but these concentrations were much higher than when no lipid was available. Therefore, such compounds, or their breakdown products, might have been reacting with other components via Maillard reaction. However, in the absence of lipids, no 2-pentylpyridine, 2-pentylthiophene, 2-hexylthiophene, and 2-pentyl-(2H)-thiapyran were present in their volatiles while in the presence of BPL, their contents were considerably higher than when BTAG were included. Similar conclusions could be reached for pyrrole, pyrazine, thiazole, thiolane and oxazole compounds with alkyl derivatives in different positions. Therefore, flavor of cooked meat arises from a complex series of reactions involving both Maillard reaction and lipid breakdown products. As demonstrated, compounds contributing to the roasted flavor notes are derived from Maillard reaction whereas those responsible for species-specific character are formed from lipid degradation (Mottram, 1998). Xu et al. (2011) found that presence of lard in cysteine and xylose model system reduced the formation of sulfur-containing compounds such as 2-methyl-3-furanthiol, 2-furanmethanethiol, 2-methylthiophene, and 3-methylthiophene from the Maillard reaction. The level of furfural in lard with cysteine and xylose model system was also less than that without lard. In addition, they also evaluated the effect of cysteine and xylose on production of oxidation products. They found that oxidation products were influenced by the presence of cysteine and xylose. More lipid-derived alcohols, alkylfurans, and acid were generated, whereas less aldehydes were produced in the presence of cysteine and xylose compared to the lard only containing system.

Compounds produced from the reactions of intermediates in- 


\section{Linoleic acid}
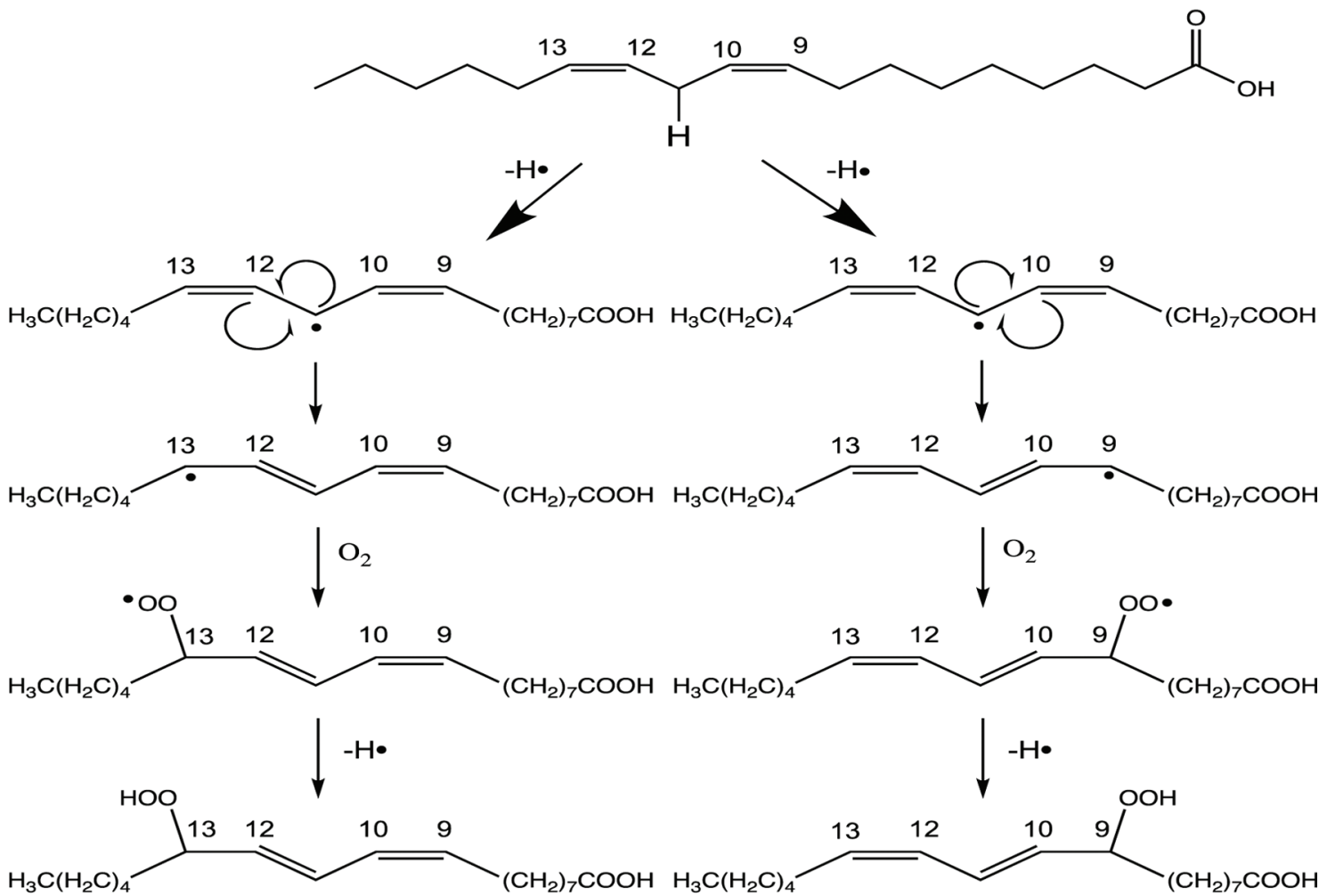

13-Hydroperoxide

9-Hydroperoxide
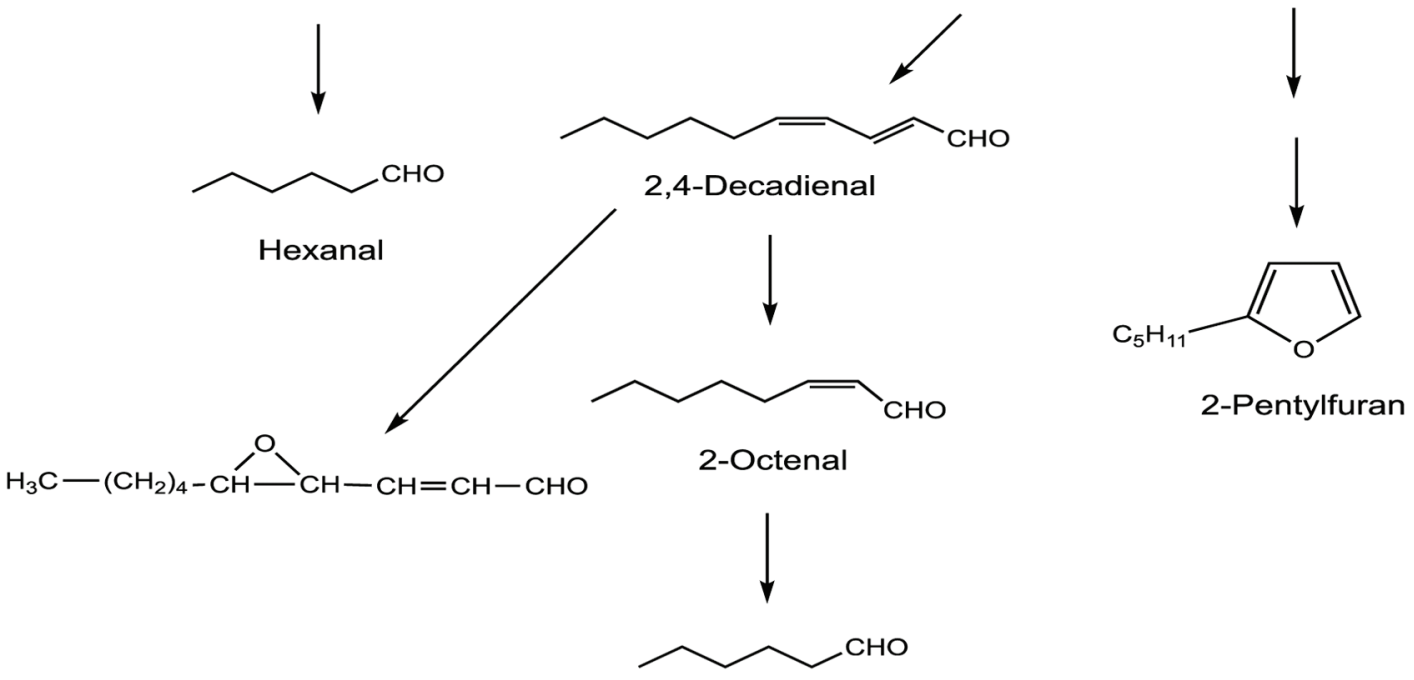

Hexanal

Figure 1. Formation of hexanal, 2,4-decadienal, 2-octenal and 2-pentylfuran from autoxidation of linoleic acid.

volved in the Maillard reaction and lipid degradation products were already noted to be alkyl substituted pyridines, thiophenes, thiazols and thiazolines, among others. These compounds may contribute to the aroma of all cooked meat by their own effect or indirectly by influencing the formation of other flavor active compounds in the Maillard reaction (Mottram, 1998; Shahidi, 1994; Arshad et al., 2018). Thus, the effects observed are complex and continue to be important both from a fundamental as well as ap- plied viewpoints.

It is important to mention the potential positive effects of the presence of a minimum amount of oxidation products in aroma generation in certain foods. As examples, the aroma generated upon preparation of French fries and donuts and perceived by consumers is due to the interaction of lipid oxidation products with the free amino acids present in the raw material. Therefore, it is important to pay particular attention to all positive as well as del- 
R: $\mathrm{C}_{5} \mathrm{H}_{11}$
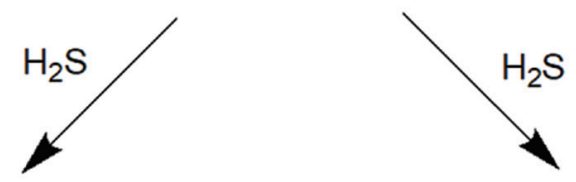<smiles>[R]CC(S)/C=C/C=O</smiles><smiles>[R]C(S)/C=C\CC=O</smiles>

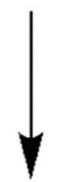

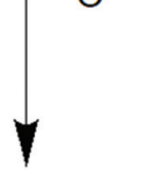<smiles>[R]CC1C=CC(O)S1</smiles><smiles>[R]C1CC=CC(O)S1</smiles><smiles>CCC(C)C=O</smiles>

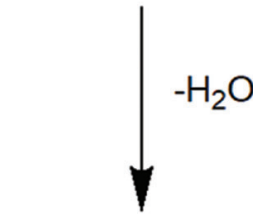<smiles>[R]Cc1cccs1</smiles><smiles>[R]C1C=CC=CS1</smiles>

Figure 2. Formation of alkyl substituted heterocyclic, 2-hexylthiophere and 2-pentyl (2H-) thiapyran from 2,4-alkadienal with hydrogen sulfide (adopted from Farmer and Mottram, 1990).

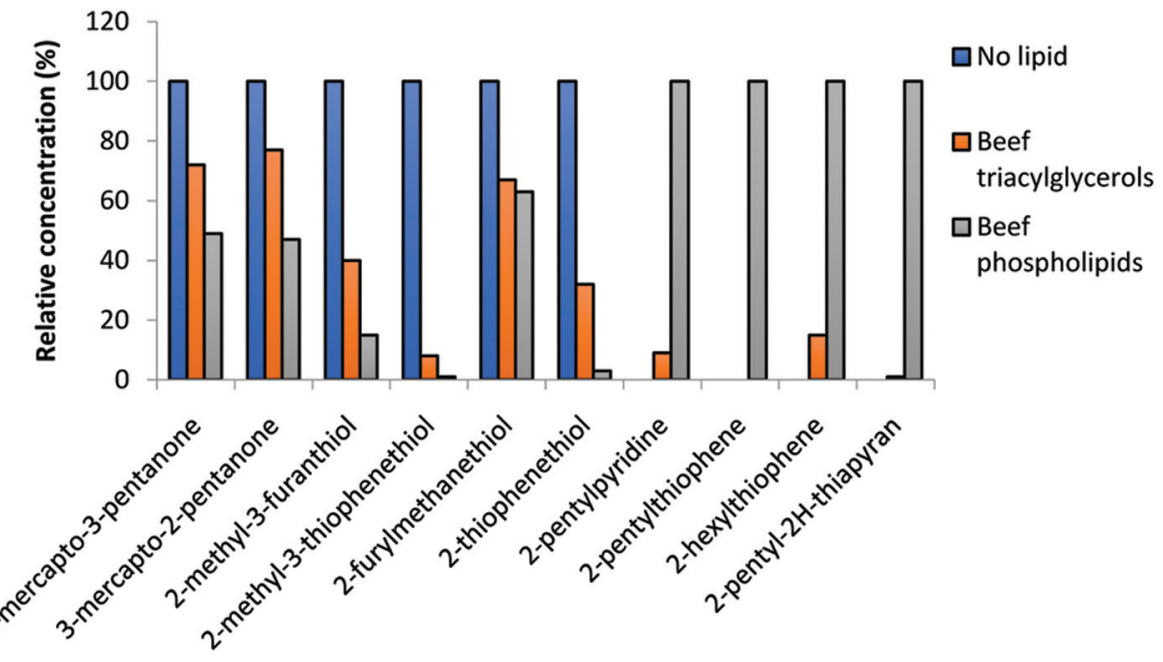

Figure 3. Relative concentration (\%) of selected acyclic and heterocyclic compounds formed by the reaction between cysteine and ribose in the absence or presence of beef triacylglycerols and beef phospholipids (data from ref. Mottram, 1998; Farmer et al., 1989; Farmer and Mottram, 1990). 
eterious effects of lipid oxidation products in flavor and off-flavor generation in foods.

\section{Relationship between secondary oxidative products of lipid and Strecker degradation}

Strecker (1862) observed that $\alpha$-amino acids degraded upon contact with alloxan, a cytotoxic analog of glucose [5,5-dihydroxyl pyrimidine-2,4,6-trione] (Ighodaro et al., 2017) then produced $\mathrm{NH}_{3}, \mathrm{CO}_{2}$, and one carbon less aldehyde (Rizzi, 1999). This reaction is called Strecker degradation, and plays an important role in the formation of volatile compounds of food flavors such as Strecker aldehydes, pyrazines, pyridines, pyrroles, and oxazoles. Hidalgo and Zamora (2004) hypothesised that secondary products of lipid oxidation which contain a dicarbonyl group at $\alpha$-carbon could also be involved in the degradation of amino acids. In order to test their hypothesis, 4,5-epoxy-2-alkenals and phenylalanine were employed. They reported that the flavor compounds which were known to be produced by the Maillard reaction might also be formed by lipid oxidation. The secondary oxidation products of lipid were able to form the Strecker aldehydes. The authors studied the formation of Strecker-type degradation using different types of secondary product of lipid oxidation such as methyl 9,10-epoxy-13-oxo-11-octadecenoate and methyl 12,13-epoxy9-oxo-11-octadecenoate and found that other lipid oxidation products could decompose the amino acids by Strecker-type degradation (Zamora et al., 2007). In addition, amino acids (cysteine and serine) and phenolic compounds can also affect the formation of Strecker aldehydes (Hidalgo and Zamora, 2004; Hidalgo et al., 2013; Rizzi, 2006). According to Rizzi (2006), quinones, derived from phenolic compounds which contain catechol, and amino acids could form flavor-important volatile aldehydes via Strecker degradation in a non-enzymetic model system. They found that phenolic compounds (caffeic acid, chlorogenic acid, catechin, and epicatechin) were able to react with amino acids (methionine and phenylalanine) and generate Strecker aldehydes (methional and phenylacetaldehyde) in the ferricyanide-based model system. This is an important consideration for plant foods as raw material and participation of their bioactive phenolics in flavor generation.

The different types of reactants originating from different sources can have their own mechanism, which may contribute to the generation of diverse flavor compounds (Delgado et al., 2016). This may be an explanation of the endless production of flavor compounds during Strecker degradation. However, one study (Delgado et al., 2016) found that $m$-diphenols (resorcinol, 2,6-dihydroxybenzoic acid, and phloroglucinol) were able to react with 2-pentenal (reactant) as well as phenylacetaldehyde (resultant), therefore they observed a decreased amount of phenylacetaldehyde in the presence of phenolic compounds mentioned above. They suggested that this result might be used for controlling the flavor formation by lipid-derived carbonyl compounds.

\section{Flavor volatiles of processed meat}

Processing of food leads to the generation of a large number of volatile compounds, each having a different impact on the overall flavor sensation that it displays. As an example, several hundred compounds have been identified in the volatile constituents of heat processed foods, including those of plant origin and also muscle foods, many of which are derived from lipid degradation (Mottram, 1998). Thus, the role of lipids in the latter group, both adipose tissue and fat contained within the lean in meat flavor has been considered with great interest. In the early sixties, Hornstein and Crowe $(1960,1963)$ found that aqueous extracts of red meat from beef, pork and lamb had similar aroma when heated while thermal processing of their corresponding fat yielded speciesspecific aromas. These authors suggested that while the lean was responsible for the basic meat flavor common to all species, species-character aromas were generated from lipid constituents. Of course, this is an over-simplification of the contribution of lipids to flavor of muscle foods as will be explained further in subsequent sections. In general, lipid-derived aroma compounds are generated from oxidation of unsaturated fatty acids present, but some oxidation products may also subsequently participate in Maillard reaction. The phospholipids in the intramuscular lipids which contain a higher percentage of unsaturated fatty acids than triacylglycerols are an important source of volatiles generated upon cooking (Farmer and Mottram, 1990). Of these lipid-derived products, saturated and unsaturated aldehydes with $\mathrm{C} 5-\mathrm{C} 10$ are major volatile components of all cooked meats and, as already noted, the characteristic flavor of different meat species is believed to be derived from lipid sources. The latter is exemplified by the presence of methyl branched saturated fatty acids such as 4-methyloctanoic and 4-methylnonanoic acids in sheep and goat meat (Wong et al., 1975).

Among the volatile compounds derived from lipids in meat, hexanal is a dominant aldehyde and is generally found together with 2,3-octanedione (Shahidi and Pegg, 1994). Hexanal is produced from the oxidation of linoleic and arachidonic acids which are omega- 6 fatty acids. This is formed directly from linoleic or arachidonic acids or indirectly from 2,4-decadienal which is another breakdown product from oxidation of the omega- 6 fatty acids (Fig. 1). However, seafoods which contain high amounts of omega-3 fatty acids produce propanal and propenal (acrolein) which are dominant short-chain aldehydes and these could be used as markers of oxidation despite their minimal or no direct effect on flavor (Wang and Cui, 2015).

Warmed-over flavor (WOF) or the off-flavor note in meats, especially poultry, upon only a few hours of refrigerated storage of such cooked products, is of interest. Tims and Watts (1958) first coined the off-flavor of reheated meat as WOF, although this definition may be expected to include other stored products. Thus, the aroma profile of stored fresh meat, although somewhat different from that of the characteristic WOF of reheated meat, includes compounds which are qualitatively the same, but present at different concentrations. Needless to say, WOF is a major concern for the hotel/restaurant/institution (HRI) food service industries. Moreover, the consumption trend has been increasing towards ready-toeat meals, therefore WOF of reheated meat after chilled storage is of interest to the public (Yang et al., 2002). The WOF has also been referred to as meat flavor deterioration (MFD) by USDA researchers (Spanier et al., 1988) who found that such a process not only involved oxidation of lipid constituents in meat, but also included degradation of proteins, and important odor impact compounds of cooked meats. Kerler and Grosch (1996) investigated the odorant of WOF of refrigerated cooked beef. They found that WOF was due to the decrease of desired odorant (4-hydroxy-2,5-dimethyl$3(2 \mathrm{H})$-furanone and 3-hydroxy-4,5-dimethyl-2(5H)-furanone) and increase of lipid oxidation products (n-hexanal and $(E)-4,5$-epoxy(E)-2-decenal). Shahidi and co-workers (Shahidi, 1991; Shahidi 1992; Shahidi and Pegg, 1992) in dealing with nitrite-free cured meats, proposed that the flavor of cooked cured meat was in fact the basic flavor of meat without being influenced by the overtone from aldehydes and other oxidation products that are generally produced during storage of thermally processed uncured meats 
<smiles>[R]c1cccs1</smiles>

thiophenes<smiles>[R]c1nc([R])c([R])s1</smiles>

thiazoles

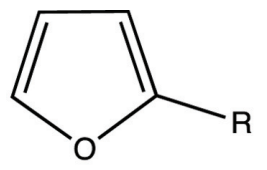

alkylfurans

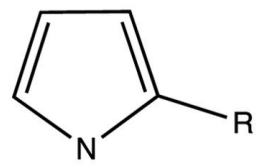

pyrroles<smiles>[R]c1nc([R])c([R])nc1[R]</smiles>

pyrazines

Figure 4. The basic structure of heterocyclic flavor compounds in cooked meat.

(Fig. 4). The basic meat curing ingredients include sodium nitrite (and/or sodium nitrate), sodium chloride, sugar, sodium ascorbate or erythrobate), polyphosphates and seasoning. These ingredients, more specifically sodium nitrite, are believed to be responsible for imparting the characteristic pink color of cooked cured-meats and contribute to the delicate flavor associated with cured meat (Pegg and Shahidi, 2000). In addition, sodium nitrite also acts as a potent antioxidant and prevents WOF development, thereby extending the shelf-life of cooked meat products. Together with salt, nitrite provides bacteriostatic action against spore germination of C. botulinum. In this relation, it is reported that the antioxidant action of nitrite might be duplicated by the use of curing adjuncts, as reflected in the level of thiobarbituric acid reactive substances (TBARS) as well as other oxidation product markers (Shahidi, 2002). The content of selected volatile compounds was also very similar when comparing adjuncts in the curing mixture, together with that of the pre-formed cooked cured-meat pigment (CCMP) which also has its own antioxidant effect, without that of nitrite. Thus, the action of nitrite in the control of MFD may not be unique (Fig. 5). In addition, when plant-based protein extenders are used in formulated meat products and sausages, their endogenous phenolic compounds may also exert an effect on flavor characteristics of the products although this effect might be minimal as these are generally added to the formulation at a level of $2 \%$ (Greuell, 1974; Shahidi et al., 1993).

In an interesting recent study, Patinho et al. (2019) used $\mathrm{Aga-}$ ricus bisporus mushroom as a potential source of natural antioxidant, fat/salt substitute, and flavor enhancer. They reported that the mixture containing the lowest fat content, a moderate amount of mushroom, and the highest concentration of salt showed the best oxidative stability. Furthermore, mushroom and salt were the main components primarily responsible for the observed sensory effects and changes. Therefore, they concluded that mushroom could potentially be used to partially reduce fat content.

\section{Flavor of roasted coffee}

On the plant material side, coffee flavor has been extensively studied, however its key flavor compounds have not yet been fully identified due to its complexity (Sunarharum et al., 2014). Among commercial processing operations, roasting plays a critical role in flavor formation and is associated with generation of nearly one thousand chemical compounds (Yanagimoto et al., 2002; Sunarharum et al., 2014; Yang et al., 2016). Upon roast-

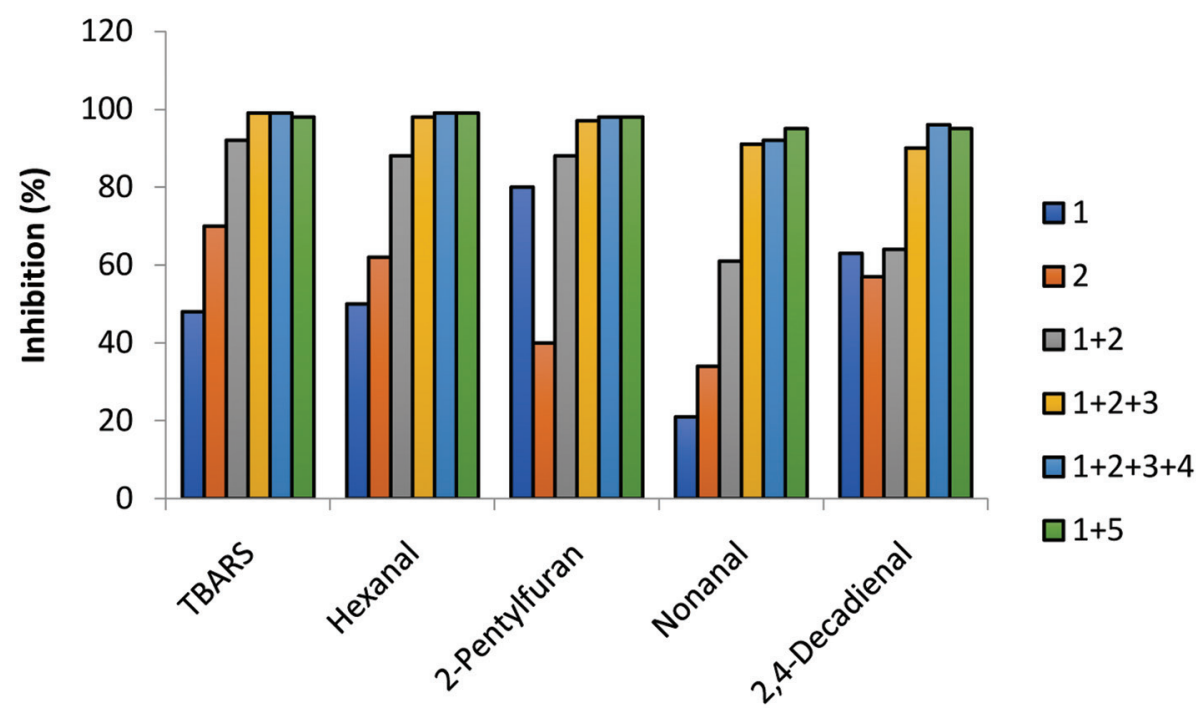

Figure 5. Inhibitory effect on the generation of selected volatile oxidation products in nitrite- and nitrite-free cured meats (adopted from Shahidi, 2002). TBARS, 2-thiobarbituric acid reactive substances; 1 , sodium ascorbate; 2, sodium tripolyphosphate; 3, cooked cured-meat pigment; 4, t-butylhydroquinone; and 5 , sodium nitrite. 
ing, numerous chemical reactions occur such as Maillard reaction, Strecker degradation, breakdown of polysaccharides, sugars, amino acids, and lipids (Buffo and Cardelli-Freire, 2004). Czerny and Grosch, (2000) compared the odorant of Arabica coffee before and after roasting. They reported that 3-isobutyl-2-methoxypyrazine, 2-methoxy-3,5-dimethylpyrazine, ethyl 2-methylbutyrate, ethyl 3-methylbutyrate, and 3-isopropyl-2-methoxypyrazine were possible odorant of raw coffee. Among these, 3-isobutyl-2-methoxypyrazine showed the highest odor activity. After roasting, the level of methional, 3-hydroxy-4,5-dimethyl-2(5H)-furanone, vanillin, $(E)-\beta$-damascenone, and 4-vinyl- and 4-ethylguaiacol were increased, whereas 3-isobutyl-2-methoxypyrazine remained the same as that in the raw coffee. Baggenstoss et al. (2008) studied the effect of time-temperature conditions on aroma formation during roasting. They found that physical properties and kinetics of aroma formation was different between low temperature-long time roasting and high temperature-short time roasting. In addition, the color of the roasted coffee bean did not represent the same aroma and physical properties (density, roast loss, and water content).

Although main flavour is developed by Maillard reaction, the overall sensation we perceive is responsible for the aroma of roasted coffee. These, like those of muscle foods, are also impacted by the generation of a large number of heterocyclic compounds with extremely low-threshold values and hence the impact they have is not just concentration dependent but primarily imposed by their chemical nature and the threshold value of each (Shahidi, 2002).

Lipids in roasted coffee, known as coffee oil, carry most of the coffee aroma. The lipids move to bean's surface during roasting and are extracted when coffee is brewed (Sunarharum et al., 2014). These form the so called "crema" emulsion which provides flavor volatiles, texture, and mouthfeel (Oestreich-Janzen, 2010). In addition, furan, a frequently identified volatile compound in roasted coffee, can be formed not only from thermal degradation of sugar but also via thermal oxidation of lipids (Yang et al., 2016). Furthermore, oxidation products of lipids may participate in the generation of certain Maillard reaction products, thus impacting the overall flavor of roasted coffee.

Linoleic and palmitic acids are the major fatty acids in coffee. Linoleic acid, a polyunsaturated fatty acid, is susceptible to oxidation especially when coffee beans are subjected to the roasting process. Typical secondary oxidation products such as 2-octenal, 2,4-decadienal, 2,4-heptadienal, 4-hydroxynonenal, and 4,5-epoxy-2-decenal are found in roasted coffee in high concentrations (Kocadağl1 et al., 2012). Furthermore, the amounts of 2-octenal, 2,4-decadienal, 2,4-heptadienal were increased during roasting in a time-dependent manner. In addition, chlorogenic acid and other phenolics present in coffee might influence the overall flavor of coffee due to their potential effect on taste of coffee beverages (Izawa et al., 2010) and potential interaction with lipids and their derived products.

\section{Beany flavor in soybean products}

Soybean is an important legume that has been utilized in many different ways in food such as oil, flour, soymilk, tofu, fermented bean paste, and soy sauce, as well as animal meal and nutraceuticals and functional foods. However, a beany flavor is noted upon ageing of the oil and in products such as soymilk and other soybased products. This phenomenon of beany, grassy, and paint-like flavor is called reversion. Hoffmann (1961) reported beany flavor was due to 3-(Z)-hexenal, but this was not the case as its concentration in oxidized oil was very low and the results could not be confirmed (Krishnamurthy et al., 1967). Chang et al. (1966) found 2-pentylfuran in slightly oxidized soybean oil and later Krishnamurthy et al. (1967) reported that 2-pentylfuran was a key compound with beany flavor when present at $1-10 \mathrm{ppm}$. However, although it was a dominant volatile in slightly oxidized soybean oil, it was not a dominant one in cottonseed oil and hence its importance in cottonseed oil was not evident. Later, Ho et al. (1978) synthesized $(Z)$ and $(E)$-2-(1-pentenyl) furan and examined their organoleptic properties. They confirmed that these compounds at a concentration of $8 \mathrm{ppm}$ and $2 \mathrm{ppm}$, respectively, could contribute to the reversion flavor of soybean oil. Min et al. (2003) reported that 2-pentylfuran and 2-pentenylfuran were found, by solid-phase microextraction-gas chromatography-mass spectrometry, in oxidized soybean oil containing $5 \mathrm{ppm}$ chlorophyll. The level of these compounds was elevated as light exposure time and chlorophyll concentration increased. Lee and Min (2010) found 2-pentylfuran in chlorophyll photosensitized linoleic acid.

Dutton et al. (1951) hypothesized that the precursor of beany flavor in soy products was linolenic acid, however, Krishnamurthy et al. (1967) suggested that linoleic acid, a dominant fatty acid in soybean oil, was the source. Smouse and Chang (1967) examined the volatile compounds in reverted soybean oil at a $4.3 \mathrm{meq} / \mathrm{kg}$ of peroxide value and identified a total of 71 volatile compounds, mainly formed by autoxidation of oleic and linoleic acids and suggested that linolenic acids in soybean oil might affect the autoxidation of linoleic acid and change the degradation pattern of its hydroperoxides. Volatile compounds in soybean products are summarized in Table 1. Furthermore, using soy protein in food formulations may make an indirect contribution to flavor as well as presence of bioactive compounds. The isoflavones in soy might affect lipid stability and hence the overall impact on flavor (Drewnowski and Gomez-carneros, 2000). Zhang et al. (2012) evaluated the effect of soybean variety, grinding, and heat-processing of soymilk on the off-flavor generation. They reported that a combination of hot grinding and two-phase ultrahigh temperature $\left(120^{\circ} \mathrm{C} / 80 \mathrm{~s}+\right.$ $140{ }^{\circ} \mathrm{C} / 4 \mathrm{~s}$ ) showed that most of the odor compounds were present in less than the limit of detection. Especially ambient grinding had the highest 2-pentylfuran, followed by cool and heat grinding method. They suggested that the heat inactivated the lipoxygenases and this might partly reduce the production of 2-pentylfuran.

\section{Fishy, fusty/musty off-flavor in non-fish oils}

The beany flavor perceived from other soy products such as soymilk is also due to the lipid oxidation products but a fishy odor often perceived is due to the presence and interaction of non-lipid components with lipid oxidation products. Jiang et al. (2016) reported that trimethylamine (TMA) formed from phosphatidylcholine (PC) was responsible for fishy off-flavor in soybean oil when present together with other components. This was particularly noticed for rapeseed/canola oil in which ammonia was generated from the breakdown of glucosinolates and/or sinapine. This was nicely demonstrated by Matheis and Granvogl (2019a) in their recent research findings. In addition, the authors (Matheis and Granvogl, 2016) also found that the main difference of key odorant between desired sensory attributes and fusty/musty off-flavor in rapeseed oils was the discrepancy of concentration of certain compounds, such as 2- and 3-methylbutanoic acid, 2-methoxyphenol, and ethyl 2-methylbutanoate. Further, they (Matheis and Granvogl, 2019b) reported that 4-methylphenol, 3-methylbutanoic acid, 2-phenylethanol, 2-ethyl-3,6-dimethylpyrazine, and 2-methylbutanoic acid could be used as marker compounds for fusty/musty off-flavor. 
Table 1. Volatile compounds found in soybean products

\begin{tabular}{|c|c|c|c|}
\hline Raw soybean (Cowan et al., 1973) & Soymilk ( Lv et al., 2011) & Cooked soymilk ( Lv et al., 2011) & Soybean oil (Steenson et al., 2002) \\
\hline Acetaldehyde & 3-Methylbutanal & Beany flavor compounds & Pentane \\
\hline n-Hexanal & 2-Ethylfuran & n-Hexanal & Pentanal \\
\hline 2-Pentanal & Pentanal & 1-Hexanol & Hexanal \\
\hline Pentanol acetate & Butyl acetate & 1-octen-3-ol & 2-Butanone \\
\hline Hydrogen sulfide & n-Hexanal & (E)-2-hexenal & Heptanal \\
\hline Acetone & D-limonene & $(E, E)$-2,4-decadienal & 2-Heptenal \\
\hline Methanol & (E)-2-pentenal & Non-beany flavor compounds & 2-Pentylfuran \\
\hline Ethanol & Heptanal & $(E)$-2-octenal & 2,4-Heptadienal \\
\hline Isopentanol & 2-Pentylfuran & Nonanal & $(E)$-2-Octenal \\
\hline n-Pentanol & $(E)$-2-hexenal & (E)-2-nonenal & Nonanal \\
\hline n-Hexanol & 1-Pentanol & & (E)-2-Nonenal \\
\hline n-Heptanol & Octanal & & 2-Decenal \\
\hline Dimethylamine & (E)-2-heptenal & & \\
\hline \multirow[t]{12}{*}{ Acetic acid } & n-Hexanol & & \\
\hline & Nonanal & & \\
\hline & (E)-2-octenal & & \\
\hline & Acetic acid & & \\
\hline & 1-octen-3-ol & & \\
\hline & Heptanol & & \\
\hline & $(E, E)$-2,4-heptadienal & & \\
\hline & Benzaldehyde & & \\
\hline & (E)-2-nonenal & & \\
\hline & $(E)$-2-decenal & & \\
\hline & $(E, E)-2,4$-nonadienal & & \\
\hline & $(E, E)$-2,4-decadienal & & \\
\hline
\end{tabular}

\section{Off-flavors in supplement capsules of omega-3 oils}

The omega-3 polyunsaturated fatty acids (PUFAs) such as $\alpha$-linolenic acid (ALA; 18:3 $\omega$-3), stearidonic acid (SDA; 18:4 $\omega-3)$, eicosapentaenoic acid (EPA; 20:5 $\omega-3)$, docosapentaenoic acid (DPA; 22:5 $\omega-3$ ), and docosahexaenoic acid (DHA; 22:6 $\omega-3$ ) have been of much interest to the public because of their numerous health beneficial effects (Shahidi and Ambigaipalan, 2018). The omega-3 PUFAs are mainly present in the blubber of marine mammals such as whales and seals, the body of fatty fish such as herring, mackerel and salmon, the liver of white lean fish such as cod and halibut, as well as algal or fungal oils (Shahidi, 2015). Among PUFAs, EPA and DHA are well known for their cardioprotective, anti-inflammatory, and immune-modulatory effects (Shahidi and Finley, 2001). For this reason, omega-3 PUFAs can be easily found in the nutraceutical market, most often in the capsule form. However, omega-3 PUFAs are very susceptible to oxidation due to their high degree of unsaturation, and readily form primary oxidation products which break down to secondary oxidation products. Jackowski et al. (2015) collected 171 PUFA supplements in Canada and assessed the international voluntary safety standards (peroxide value, $p$-anisidine value, and total oxidation (TOTOX)). The au- thors found that $50 \%$ of the tested products exceeded at least one of the voluntary recommendations. Among supplements, encapsulated form showed the highest oxidative stability. However, it is almost impossible to conduct these tests to evaluate their freshness at home. Nonetheless, consumers may cut the capsules with a razor blade and check for the presence of any extensive off-flavor, which, if present, may lead to an undesirable odor in the breath following consumption (fishy burp). According to the Global Organization for EPA and DHA Omega-3s (GOED) (2019), the main reason for potential consumers not considering taking EPA and DHA is the fishy taste.

The fishy off-flavor in the oxidized omega- 3 oils is due to the presence of secondary oxidation products, such as 2,4,7-decatrienals and other carbonyl compounds (Lindsay, 1990). Early studies reported that trimethylamine was responsible for the fishy flavor, however it was revealed that fishy flavor from trimethylamine became apparent only when it was added to oxidized fish oil at high concentrations (Stansby, 1962; Lindsay, 1990). Meijboom and Stroink (1972) first reported that $(E, Z, Z)-2,4,7$-decatrienal and (E,E,Z)-2,4,7-decatrienal were mostly responsible for the fishy odor in oxidized fish oil. Later, Karahadian and Lindsay (1989) confirmed that the isomers of $(E, Z, Z)$ and $(E, E, Z)-2,4,7$-decatrienal 
contributed to the fishy flavor.

In order to avoid oxidation of omega- 3 supplements, some technique including the use of antioxidants, minimum exposure to ambient air, using an inert gas when filling the capsules, and microencapsulation using multi-layer coacervation might be considered. However, masking of off-flavors with lemon and other flavors might be considered and these have proven effective although one report indicates possible oxidation acceleration (Jackowski et al., 2015), but we could not verify this in our own work. In addition, mixed tocopherols and other phenolic antioxidants might be added to such products and these are found effective in controlling off-odor generation in these important supplements to retain their prime quality and health benefits (Sheldon et al., 1997; Yuwanti et al., 2011).

\section{Lipid oxidation in low-moisture foods}

Water content in food is closely related to food deterioration, thus reducing water content in many foods extends their shelf life. Of course, this can affect lipid oxidation as well. If the water content is high enough to act as a solvent, metal catalysts become mobilized and start acting as pro-oxidants (Labuza et al., 1971). Water activity $\left(\mathrm{a}_{\mathrm{w}}\right)$ around $0.3-0.4$ renders the highest oxidative stability. The antioxidant activity arises from hydrogen bonding of peroxides and hydration of metal catalysts, that decreases their effectiveness; this is called the monolayer theory (Labuza et al., 1972). However, foods with very low $\mathrm{a}_{\mathrm{w}}$ can accelerate the rate of lipid oxidation. According to Reed et al. (2002), roasted peanuts at $\mathrm{a}_{\mathrm{w}}$ of 0.19 showed higher peroxide value than that at $\mathrm{a}_{\mathrm{w}}$ of 0.60 . They suggested that this might be due to the direct exposure to the oxygen as proposed by Labuza and co-workers (Labuza, et al., 1970; Labuza et al., 1971). In addition, they found that the retained peanutty flavor was more in the peanuts with higher $\mathrm{a}_{\mathrm{w}}$ during storage than the peanut at $\mathrm{a}_{\mathrm{w}}$ of 0.19 . On the other hand, the peanuts at $\mathrm{a}_{\mathrm{w}}$ of 0.19 showed more painty, cardboardy, and bitter flavor than that at $\mathrm{a}_{\mathrm{w}}$ of 0.60 . In addition, volatile compounds such as pyrazines and aldehydes were identified. The aldehydes such as pentanal, hexanal, octanal, nonanal were responsible for the painty and cardboardy flavor, whereas peanutty flavor came from pyrazines such as 2-methylpyrazine, 2,5-dimethylpyrazine, ethylpyrazine, and 2,3,5-trimethylpyrazine. The peanuts with lower $\mathrm{a}_{\mathrm{w}}$ contained more pyrazines and less aldehydes compared to those at higher $\mathrm{a}_{\mathrm{w}}$

Cereals are generally stable, however, after processing, they may experience sensory defect due to enzymatic and non-enzymatic reactions (Lehtinen et al., 2003). Among enzymes, lipoxygenase oxidizes 1,4-pentadiene moieties in polyunsaturated fatty acids (PUFAs). Rice bran, wheat germ, and oats have high activity of enzymes such as lipase and lipoxygenase, thus enzyme inactivation is necessary. Lehtinen et al. (2003) found a trend when oat kernels after heat treatment showed generation of more volatile compounds (hexanal) than oat with no heat treatment during 12 months of storage. Heiniö et al. (2002) reported that the major offflavor sensation was due to the production of volatile compounds as affected by processing and storage condition. Volatiles responsible for rancid flavor in oat were hexanal, pentanal, 3-methyl1-butanol, pentylfuran, 2-butyl-2-octenal, 2-propyl-2-octenal, $(E)$ - and $(Z)$-3-octene-2-one, $(E, E)$ - and $(E, Z)$-3,5-octadien-2-one (Heydanek and McGorrin, 1986; Molteberg et al., 1996a). In addition, it was speculated that hydroxyoctadecadienoic monoacylglycerols caused the bitter flavor in stored ground oat (Biermann and Grosch, 1979). Wheat germ is also susceptible to oxidation due to high content of PUFAs as well as activities of lipase and li- poxygenase (Sjövall et al, 2000). Sjövall et al. (2000) reported that 1-pentanol could serve as an indicator of the degree of oxidation of wheat germ and the most abundant volatiles present were hexanal, $\alpha$-pinene, 1-hexanol, and 3-carene. On the other hand, wheat flour has limited lipoxygenase activity, thus other ingredients such as beans or soya are used to improve the required activity for baking (Pozo-Bayón et al., 2006).

\section{Phenolic compound-derived flavor}

Phenolic compounds are secondary metabolites of plants and play an important role in plants by regulating growth (Shahidi and Yeo, 2018). These are added as such or as ingredients of other material to lipid-based food due to their antioxidant activity. Although the amounts of phenolic compounds are generally small, these can still affect the flavor of foods via their own taste and/or by retarding the formation of other flavor compounds, such as oxidation products (Molteberg et al., 1996b). According to Molteberg et al. (1996b), some $29 \%$ of the sensory (odor and flavor) variation in oat grouts was due to the 11 phenolic compounds identified. Phenolic compounds possess bitter and astringent taste and these are important in, but not limited to, beverage industry such as beer, wine, tea, and coffee (Soto-Vaca et al., 2012). Phenolic compounds are necessary to extend the shelf life of lipid-based foods, however their level needs to be adjusted to avoid bitterness. For example, olives are inedible due to the high amount of oleuropeins, one of their endogenous phenolic compounds. Therefore, olives should go through alkali treatment to hydrolyze oleuropeins (Johnson and Mitchell, 2019). The taste and flavor of phenolic compounds depends on the concentration and their degree of polymerization; the contribution of phenolics originating from those of oak in aged wine is a good example in this regard (Peleg et al., 1999). As noted already, phenolic compounds also affect the flavor via retarding oxidation and reducing the rate of formation of secondary oxidation products (Zhou et al., 1999). In view of the important bioactivity of phenolic compounds as natural sources of antioxidants and in functional foods, their role in flavor perception and contribution to aroma should not be ignored.

\section{Modern analysis of key aroma compounds}

Food flavor and aroma has been extensively studied and numerous volatile compounds have been identified. In fact, less than $5 \%$ of the volatiles in food can actually contribute to aromas (Grosch, 2000; Grosch, 2001; Dunkel et al., 2014). Thus, different concepts to determine odor activity values (OAVs) have been applied such as aroma extract concentration analysis (AECA), aroma extract dilution analysis (AEDA), and charm analysis (Schieberle and Grosch, 1987; Marin et al., 1988; Grosch, 2001; Reineccius and Peterson, 2013). Among these, AEDA is the most popular method and considered as a first step due to its simplicity (Ferreira et al., 2002). According to AEDA, the flavor extracts diluted then analyzed by gas chromatography-olfactometry (GCO) and the results are expressed by flavor dilution (FD) factor. The maximum dilution is determined by at least one of the judges. Song and Cadwallader (2008) studied aroma compounds in American country ham using different techniques such as direct solvent extraction-solvent assisted flavor evaporation (DSE-SAFE), dynamic headspace dilution analysis (DHDA), and aroma extract dilution analysis (AEDA). Compounds such as 1-octen-3-one, 2-acetyl-1-pyrroline, 1-nonen-3-one, decanal, and $(E)$-2-nonenal were identified 
as major odorants (FD factor $\geq 125$ ) in DHDA method, whereas 1-octen-3-one, methional, guaiacol, $(E)-4,5$-epoxy- $(E)$-decenal, $p$ cresol, 3-methylbutanal, hexanal, 2-acetyl-1-pyrroline, phenylacetaldehyde, $\gamma$-nonalactone, short-chain volatile acids were found as dominant compounds in DSE-SAFE method. On the other hand, 3-methylbutanal, hexanal, 1-octen-3-one, 2-acetyl-1-pyrroline, methional, $(Z)$-2-nonenal, phenylacetaldehyde, $(E, E)-2,4-$ decadienal, guaiacol, 2-phenylethanol, $(E)$-4,5-epoxy- $(E)$-decenal, $\gamma$-nonalactone, and $p$-cresol were predominant odorants $\left(\log _{3} \mathrm{FD}\right.$ factor $\geq 3$ ) in AEDA method. They concluded that lipid oxidation, amino acid degradation, and Maillard/Strecker and associated reactions were responsible for the generation of these compounds. Hammer and Schieberle (2013) reported key aroma compounds derived from $\omega-3$ fatty acids (ALA, EPA, and DHA) oxidation induced by copper (II) ions or lipoxygenase and then used AEDA to analyze aroma compounds. While the copper-induced oxidation of EPA and DHA produced fishy odor, ALA did not generate any unpleasant odor in both copper-induced and enzyme-induced oxidation. They found that $(E)-4,5$-epoxy-(E,Z)-2,7-decadienal, (Z)-1,5-octadien-3-one, and ( $Z$-)-3-hexenal showed the highest FD factors $(\geq 1,000)$ from EPA and DHA oxidation induced by copper ion or enzyme. In addition, $(E, E, Z)-2,4,6$-nonatrienal exhibited the highest FD factor $(\geq 1,000)$ from EPA oxidation induced by copper ion or enzyme, whereas, $(Z, Z)$-3,6-nonadienal was another dominant compound (FD factor $\geq 1,000$ ) from DHA oxidation induced by copper ion or enzyme. Meanwhile, in ALA oxidation induced by copper ion or enzyme, $(E)$-4,5-epoxy- $(E, Z)$-2,7-decadienal, $(Z)$ 3-hexenal (E,Z)-2,6-nonadienal, $(E, E, Z)-2,4,6$-nonatrienal were predominant aroma compounds (FD factor $\geq 1,000$ ). They reported that the qualitative analysis of all samples showed similarity, however the quantitative analysis was quite different. Therefore, they concluded that the ratio between the odorant might be responsible for the production of fishy off-flavor. An et al. (2020) reported that compounds such as hexanal, $(Z)$-4-heptenal, $(Z)$-4-decenal, (E,Z)-2,6-nonadienal, $(E, E)$-2,4-nonadienal, $(E, Z)$-2,4-decadienal, $(E, E)$-2,4-decadienal, $(E, E, Z)-2,4,6$-nonatrienal, $(E, Z, Z)-2,4,7-$ tridecatrienal, and $(E)-4,5$-epoxy-(E)-2-decenal in surimi were the most potent aroma-active compounds for fishy, green, oily, or metallic odors.

\section{Conclusions}

Lipids are a major source of flavor in food, both desirable and undesirable. We demonstrated in this review that lipid-derived flavor and off-flavor may be generated upon food processing via involvement of Strecker degradation and Maillard reaction, as well as oxidative processes. It is possible to control the development of off-flavor and to produce desirable flavor by better understanding of the mechanisms involved and by inclusion of bioactive or bioactive-containing components in production of novel functional foods. It is hoped that this review provides an incentive to catalyze further research and development to advance this important field that would be of interest to producers, consumers and regulatory agencies.

\section{References}

An, Y., Qian, Y.L., Magana, A.A., Xiong, S., and Qian, M.C. (2020). Comparative characterization of aroma compounds in silver carp (Hypophthalmichthys molitrix), Pacific whiting (Merluccius productus), and Alaska pollock (Theragra chalcogramma) surimi by aroma extract dilution analysis, odor activity value, and aroma recombination stud- ies. J. Agric. Food Chem. In press.

Arshad, M.S., Sohaib, M., Ahmad, R.S., Nadeem, M.T., Imran, A., Arshad, M.U., Kwon, J.H., and Amjad, Z. (2018). Ruminant meat flavor influenced by different factors with special reference to fatty acids. Lipids Health Dis. 17: 223.

Baggenstoss, J., Poisson, L., Kaegi, R., Perren, R., and Escher, F. (2008). Coffee roasting and aroma formation: Application of different timetemperature conditions. J. Agric. Food Chem. 56: 5836-5846.

Biermann, U., and Grosch, W. (1979). Bitter-tasting monoglycerides from stored oat flour. Z. Lebens. Forsch. 169: 22-26.

Buffo, R.A., and Cardelli-Freire, C. (2004). Coffee flavour: An overview. Flavour Fragr. J. 19: 99-104.

Chang, S.S., Smouse, T.H., Krishnamurthy, R.G., Mookherjee, B.D., and Reddy, B.R. (1966). Isolation and identification of 2-pentyl furan as contributing to the reversion flavor of soybean oil. Chem. Ind. 46: 1926-1927.

Chen, B., McClements, D.J., and Decker, E.A. (2011). Minor components in food oils: A critical review of their roles on lipid oxidation chemistry in bulk oils and emulsions. Crit. Rev. Food Sci. Nutr. 51: 901-916.

Choe, E., and Min, D.B. (2006). Mechanisms and factors for edible oil oxidation. Compr Rev Food Sci Food Saf. 5: 169-186.

Cowan, J.C., Rackis, J.J., and Wolf, W.J. (1973). Soybean protein flavor components: A review. J. Am. Oil Chem. Soc. S0: 426A-444A.

Czerny, M., and Grosch, W. (2000). Potent odorants of raw arabica coffee. Their changes during roasting. J. Agric. Food Chem. 48: 868-872.

Delgado, R.M., Hidalgo, F.J., and Zamora, R. (2016). Antagonism between lipid-derived reactive carbonyls and phenolic compounds in the Strecker degradation of amino acids. Food Chem. 194: 1143-1148.

Drewnowski, A., and Gomez-Carneros, C. (2000). Bitter taste, phytonutrients, and the consumer: a review. Am. J. Clin. Nutr. 72: 1424-1435.

Dunkel, A., Steinhaus, M., Kotthoff, M., Nowak, B., Krautwurst, D., Schieberle, P., and Hofmann, T. Nature's chemical signatures in human olfaction: A foodborne perspective for future biotechnology. Angew. Chem. Int. Ed. 53: 7124-7143.

Dutton, H.T., Lancaster, C.R., Evans, C.D., and Cowan, T.C. (1951). The flavor problem of soybean oil. VII. Linolenic acid. J. Am. Oil Chem. Soc. 28: $115-118$.

Farmer, L.J., and Mottram, D.S. (1990). Interaction of lipid in the Maillard reaction between cysteine and ribose: The effect of a triglyceride and three phosphlipids on the volatile products. J. Sci. Food Agric. 53 505-525.

Farmer, L.J., Mottram, D.S., and Whitfield, F.B. (1989). Volatile compounds produced in maillard reactions involving cysteine, ribose and phospholipid. J. Sci. Food Agric. 49: 347-368.

Ferreira, V., Pet'ka, J., and Aznar, M. (2002). Aroma Extract Dilution Analysis. Precision and Optimal Experimental Design. J. Agric. Food Chem. 50: $1508-1514$

Greuell, E.H.M. (1974). Some aspects of research in the application of soy proteins in foods. J Am. Oil Chem, Soc. 51: 98A-100A.

Grosch, W. (2000). Specificity of the human nose in perceiving food odorants. In: Schieberle, P., and Engel, K.-H. (Ed.). Frontiers of flavour science. Proceedings of the Ninth Weurman Flavour Research Symposium, Deutsche Forschungsanstalt für Lebensmittelchemie, Garching. pp. 213-219.

Grosch, W. (2001). Evaluation of the key odorants of foods by dilution experiments, aroma models and omission. Chem. Sences 26: 533-545.

Hammer, M., and Schieberle, P. (2013). Model studies on the key aroma compounds formed by an oxidative degradation of $\omega-3$ fatty acids initiated by either copper (II) ions or lipoxygenase. J. Agric. Food Chem. 61: 10891-10900.

Heiniö, R.-L., Lehtinen, P., Oksman-Caldentey, K.-M., and Poutanen, K. (2002). Differences between sensory profiles and development of rancidity during long-term storage of native and processed oat. Cereal Chem. 79: 367-375.

Heitmann, M., Zannini, E., Axel, C., and Arendt, E. (2017). Correlation of flavor profile to sensory analysis of bread produced with different Saccharomyces cerevisiae originating from the baking and beverage industry. Cereal Chem. 94: 746-751.

Heydanek, M.G., and McGorrin, R.J. (1986). Oat flavor chemistry: Principles and prospects. In: Webster, F.H. (Ed.). Oats: Chemistry and technology. . American Association of Cereal Chemists, St. Paul, MN, pp. 
335-369.

Hidalgo, F.J., Alcón, E., and Zamora, R. (2013). Cysteine- and serine-thermal degradation products promote the formation of Strecker aldehydes in amino acid reaction mixtures. Food Res. Int. 54: 1394-1399.

Hidalgo, F.J., and Zamora, R. (2004). Strecker-type degradation produced by the lipid oxidation products 4,5-epoxy-2-alkenals. J. Agric. Food Chem. 52: 7126-7131.

Ho, C.-T., and Chen, Q. (1994). Lipids in food flavors. In: Ho, C.-T., and Hartman, T.G. (Ed.). Lipids in Food Flavors. ACS Symposium Series. American Chemical Society, Washington, DC, pp. 1-14.

Ho, C.-T., Smagula, M.S., and Chang, S.S. (1978). The synthesis of 2-(1-pentenyl) furan and its relationship to the reversion flavor of soybean oil. J. Am. Oil Chem. Soc. 55: 233-237.

Hodge, J.E. (1953). Chemistry of browning reactions in model systems. J. Agric. Food Chem. 1: 928-943.

Hoffmann, G. (1961). 3-cis-hexenal, the "green". reversion flavor of soybean oil. J. Am. Oil Chem. Soc. 38: I-4.

Hornstein, I., and Crowe, P.F. (1960). Flavour studies on beef and pork. J. Agric. Food Chem. 8: 494-498.

Hornstein, I., and Crowe, P.F. (1963). Meat flavour: Lamb. J. Agric. Food Chem. 11: 147-149.

Ighodaro, O.M., Adeosun, A.M., and Akinloye, O.A. (2017). Alloxaninduced diabetes, a common model for evaluating the glycemiccontrol potential of therapeutic compounds and plants extracts in experimental studies. Medicina 53: 365-374.

Izawa, K., Amino, Y., Kohmura, M., Ueda, Y., and Kuroda, M. (2010). Human-environment interactions-taste. In: Mander, L. (Ed.). Comprehensive Natural Products II: Chemistry and Biology. Elsevier Science \& Technology, Amsterdam, Netherlands, pp. 631-671.

Jackowski, S.A., Alvi, A.Z., Mirajkar, A., Imani, Z., Gamalevych, Y., Shaikh, N.A., and Jackowski, G. (2015). Oxidation levels of North American over-the-counter n-3 (omega-3) supplements and the influence of supplement formulation and delivery form on evaluating oxidative safety. J. Nutr. Sci. 4: e30

Jiang, X., Jin, Q., Wu, S., and Wang, X. (2016). Contribution of phospholipids to the formation of fishy offodor and oxidative stability of soybean oil. Eur. J. Lipid Sci. Technol. 118: 603-611.

Johnson, R., and Mitchell, A.E. (2019). Use of amberlite macroporous resins to reduce bitterness in whole olives for improved processing sustainability. J. Agric. Food Chem. 67: 1546-1553.

Karahadian, C., and Lindsay, R.C. (1989). Evaluation of compounds contributing characterizing fishy flavors in fish oils. J. Am. Oil Chem. Soc 66: 953-960.

Kerler, J., and Grosch, W. (1996). Odorants contributing to warmed-over flavor (WOF) of refrigerated cooked beef. J. Food Sci. 61: 1271-1275.

Kerscher, R., and Grosch, W. (1998). Quantification of 2-methyl-3-furanthiol, 2-furfurylthiol, 3-mercapto-2-pentanone, and 2-mercapto-3-pentanone in heated meat. J. Agric. Food Chem. 46: 1954-1958.

Kocadağlı, T., Göncüoğlu, N., Hamzalıŏlu, A., and Gökmen, V. (2012). In depth study of acrylamide formation in coffee during roasting: role of sucrose decomposition and lipid oxidation. Food and Funct. 3: 970-975.

Krishnamurthy, R.G., Smouse, T.H., Mookherjee, B.D., Reddy, B.R., and Chang, S.S. (1967). Identification of 2-pentyl furan in fats and oils and its relationship to the reversion flavor of soybean oil. J. Food Sci. 32: 372-374.

Labuza, T.P., Heidelbaugh, N.D., Silver, M., and Karel, M. (1971). Oxidation at intermediate moisture contents. J. Am. Oil Chem. Soc. 4: 86-90.

Labuza, T.P., McNally, L., Gallagher, D., Hawkes, J., and Hurtado, F. (1972). Stability of intermediate moisture foods. 1. Lipid oxidation. J. Food Sci. 37: 154-159.

Labuza, T.P., Tannenbaum, S.R., and Karel, M. (1970). Water content and stability of low moisture and intermediate moisture foods. Food Technol. 24: 35-42.

Lee, J.H., and Min, D.B. (2010). Analysis of volatile compounds from chlorophyll photosensitized linoleic acid by headspace solid-phase microextraction (HS-SPME). Food Sci. Biotechnol. 19: 611-616.

Lee, L.W., Cheong, M.W., Curran, P., Yu, B., and Liu, S.Q. (2015). Coffee fermentation and flavor-An intricate and delicate relationship. Food Chem. 185: 182-191.

Lehtinen, P., Kiiliäinen, K., Lehtomäki, I., and Laakso, S. (2003). Effect of heat treatment on lipid stability in processed oats. J. Cereal Sci. 37: 215-221.

Li, Q., Wang, J., and Shahidi, F. (2016). Chemical characteristics of coldpressed blackberry, black raspberry, and blueberry seed oils and the role of the minor components in their oxidative stability. J. Agric. Food Chem. 64: 5410-5416.

Lindsay, R.C. (1990). Fish flavor. Food Rev. Int. 6: 437-455.

Lv, Y.-C., Song, H.-L., Li, X., Wu, L., and Guo, S.-T. (2011). Influence of blanching and grinding process with hot water on beany and nonbeany flavor in soymilk. J. Food Sci. 76: S20-S25.

Maillard, L.C. (1912). Action des acides aminés sur les sucres; formation des méla-noidines par voie methodique. Comptes Rendus. 154: 66-68.

Marin, A.B., Acree, T.E., and Barnard, J. (1988). Variation in odor detection thresholds determined by charm analysis. Chemical Senses 13 : 435-444.

Matheis, K., and Granvogl, M. (2016). Characterization of key odorants causing a fusty/musty off-flavor in native cold-pressed rapeseed oil by means of the sensomics approach. J. Agric. Food Chem. 64: 8168-8178.

Matheis, K., and Granvogl, M. (2019a). Unraveling of the fishy off-flavor in steam-treated rapeseed oil using the sensomics concept. J. Agric. Food Chem. 67: 1484-1494.

Matheis, K., and Granvogl, M. (2019b). Differentiation between aromarelated bioactives in native cold-pressed rapeseed oils with desired sensory attributes and with a fusty/musty off-flavor using multivariate methods. J. Food Bioactives 8: 51-57.

McClements, D.J., and Decker, E.A. (2007). Lipids. In: Damodaran, S., Parkin, K.L., and Fennema, O.R. (Ed.). Fennema's Food Chemistry. CRC Press, Boca Raton, FL, USA, pp. 155-216.

Meijboom, P.W., and Stroink, J.B.A. (1972). 2-trans,4-cis,7-cis-Decatrienal, the fishy off-flavor occurring in strongly autoxidized oils containing linolenic acid or $\omega-3,6,9$, etc., fatty acids. J. Am. Oil Chem. Soc. 47 : 555-558.

Min, D.B., Callison, A.L., and Lee, H.O. (2003). Singlet oxygen oxidation for 2-pentylfuran and 2-pentenylfuran formation in soybean oil. J. Food Sci. 68: 1175-1178.

Molteberg, E.L., Magnus, E.M., Bjørge, J.M., and Nilsson, A. (1996a). Sensory and chemical studies of lipid oxidation in raw and heat-treated oat flours. Cereal Chem. 73: 579-587.

Molteberg, E.L., Solheim, R., Dimberg, L.H., and Frølich, W. (1996b). Variation in oat groats due to variety, storage and heat treatment. II. Sensory quality. J. Cereal Sci. 24: 273-282.

Mottram, D.S. (1994). Flavour compounds formed during the Maillard re action. In: Parliament, T.H., Morello, M.J., and McGorrin, R.J. (Ed.). Thermally generated flavours: Maillard, microwave, and extrusion processes. ACS Symposium Series. American Chemical Society Washington, DC, pp. 104-126.

Mottram, D.S. (1994). Some aspects of the chemistry of meat flavour. In: Shahidi, F. (Ed.). The flavour of meat and meat products. Springer US, Boston, MA, pp. 210-230.

Mottram, D.S. (1998). Flavour formation in meat and meat products: A review. Food Chem. 62: 415-424.

Mottram, D.S., and Edwards, R.A. (1983). The role of triglyceride and phospholipids in the aroma of cooked beef. J. Sci. Food Agric. 34: 517-522.

Oestreich-Janzen, S. (2010). Chemistry of coffee. In: Lew, M., and HungWen, L. (Ed.). Comprehensive natural products II. Vol. 3. Elsevier, Amsterdam, Netherlands, pp. 1085-1117.

Pan, D.D., Wu, Z., Peng, T., Zeng, X.Q., and Li, H. (2014). Volatile organic compounds profile during milk fermentation by Lactobacillus pentosus and correlations between volatiles flavor and carbohydrate metabolism. J. Dairy Sci. 97: 624-631.

Patinho, I., Saldaña, E., Selani, M.M., de Camargo, A.C., Merlo, T.C., Menegali, B.S., de Souza Silva, A.P., and Contreras-Castillo, C.J. (2019). Use of Agaricus bisporus mushroom in beef burgers: antioxidant, flavor enhancer and fat replacing potential. Food Prod. Process. Nutr. 1: 7.

Pegg, R.B., and Shahidi, F. (2000). . Nitrite curing of meat; The N-Nitrosoamine Problem and Nitrite Alternatives. Food \& Nutrition Press, Trumball, CT, pp. 105-132.

Peleg, H., Gacon, K., Schlich, P., and Noble, A.C. (1999). Bitterness and astringency of flavan-3-ol monomers, dimers and trimers. J. Sci. Food 
Agric. 79: 1123-1128.

Perez-Locas, C., and Yaylayan, V.A. (2010). The Maillard reaction and food quality deterioration. In: Skibsted, L.H., Risbo, J., and Andersen, M.L. (Ed.). Chemical Deterioration and Physical Instability of Food and Beverages. Elsevier, Amsterdam, Netherlands, pp. 70-94.

Pozo-Bayón, M.A., Guichard, E., and Cayot, N. (2006). Flavor control in baked cereal products. . Food Rev. Int. 22: 335-379.

Reed, K.A., Sims, C.A., Gorbet, D.W., and O'Keefe, S.F. (2002). Storage water activity affects flavor fade in high and normal oleic peanuts. Food Res. Int. 35: 769-774.

Reineccius, G., and Peterson, D. (2013). Principles of food flavor analysis. In: Kilcast, D. (Ed.). Instrumental assessment of food sensory quality, Instrumental assessment of food sensory quality: A practical guide. Elsevier Science \& Technology, Cambridge, Amsterdam, Netherlands.

Rizzi, G.P. (1999). The Strecker degradation and its contribution to food flavor. In: Teranishi, R., Wick, E.L., and Hornstein, I. (Ed.). Flavor chemistry. Springer, Boston, MA, pp. 335-343.

Rizzi, G.P. (2006). Formation of Strecker aldehydes from polyphenol-derived quinones and a-amino acids in a nonenzymic model system. J. Agric. Food Chem. 54: 1893-1897.

Schieberle, P., and Grosch, W. (1987). Evaluation of the flavour of wheat and rye bread crusts by aroma extract dilution analysis. Z. Lebensm. Unters. Forsch. 185: 111-113.

Shahidi, F. (1989). Flavor of cooked meats. In: Teranishi, R., Buttery, R.G., and Shahidi, F. (Ed.). Flavor Chemistry, Flavor Chemistry: Trends and Developments. ACS Symposium Series. American Chemical Society, Washington, DC, pp. 188-201.

Shahidi, F. (1991). Developing alternative meat-curing systems. Trends Food Sci. Technol. 2: 219-222.

Shahidi, F. (1992). Prevention of lipid oxidation in muscle foods by nitrite and nitrite-free compositions. In: St. Angelo, A.G. (Ed.). Lipid oxidation in food. ACS Symposium Series. American Chemical Society, Washington, DC, Washington, DC, pp. 161-182.

Shahidi, F. (1994). Flavor of meat and meat products-an overview. In: Shahidi, F. (Ed.). Flavor of meat and meat products. Springer, Boston, MA, pp. 1-3.

Shahidi, F. (2002). Lipid-derived flavors in meat products. In: Kerry, J.P., Kerry, J.F., and Ledward, D. (Ed.). Meat Processing: Improving Quality. Elsevier, Amsterdam, Netherlands, pp. 105-121.

Shahidi, F. (2015). Omega-3 fatty acids and marine oils in cardiovascular and general health: A critical overview of controversies and realities. J. Funct. Foods 19: 797-800.

Shahidi, F., and Zhong, Y. (2010). Lipid oxidation and improving the oxidative stability. Chem. Soc. Rev. 39: 4067-4079.

Shahidi, F., and Ambigaipalan, P. (2018). Omega-3 polyunsaturated fatty acids and their health benefits. Annu. Rev. Food Sci. Technol. 9: 345-381.

Shahidi, F., and Finley, J.W. (2001). Omega-3 fatty acids: Chemistry, nutrition and health effects (ACS Symposium Series). American Chemical Society, Washington, DC.

Shahidi, F., and Pegg, R.B. (1992). Nitrite-free meat curing systems: update and review. Food Chem. 43: 185-191.

Shahidi, F., and Pegg, R.B. (1994). Hexanal as an indicator of meat flavor deterioration. J. Food Lipids 1: 177-186.

Shahidi, F., and Yeo, J.D. (2018). Bioactivities of phenolics by focusing on suppression of chronic diseases: A review. Int. J. Mol. Sci. 19: 1573.

Shahidi, F., Yang, Z., Saleemi, Z.O., and Omar, S. (1993). Stabilization of mechanically deboned chicken meat lipids with ground mustard seed. J. Food Lipids 1: 89-96.

Shahidi, F., and Zhong, Y. (2015). Measurement of antioxidant activity. J. Funct. Food 18: 757-781.

Sheldon, B.W., Curtis, P.A., Dawson, P.L., and Ferket, P.R. (1997). Effect of dietary vitamin e on the oxidative stability, flavor, color, and volatile profiles of refrigerated and frozen turkey breast meat. Poult. Sci. 76: 634-641.

Sjövall, O., Virtalaine, T., Lapveteläinen, A., and Kallio, H. (2000). Development of rancidity in wheat germ analyzed by headspace gas chroma- tography and sensory analysis. J. Agric. Food Chem. 48: 3522-3527.

Smouse, T.H., and Chang, S.S. (1967). A systematic characterization of the reversion flavor of soybean oil. J. Am. Oil Chem. Soc. 44: 509-514.

Song, H., and Cadwallader, K.R. (2008). Aroma Components of American Country Ham. J. Food Sci. 73: C29-C35.

Soto-Vaca, A., Gutierrez, A., Losso, J.N., Xu, Z., and Finley, J.W. (2012). Evolution of phenolic compounds from color and flavor problems to health benefits. J. Agric. Food Chem. 60: 6658-6677.

Spanier, A.M., Edwards, J.V., and Dupuy, H.P. (1988). The warmed-over flavor process in beef: A study of meat proteins and peptides. Food Technol. 42: 110-118.

Stansby, M.E. (1962). Speculation on fishy odors and flavors. Food Technol. 16: 28.

Steenson, D.F., Lee, J.H., and Min, D.B. (2002). Solid phase microextraction of volatile soybean oil and corn oil compounds. J. Food Sci. 67: 71-76.

Strecker, A. (1862). A note concerning a peculiar oxidation by alloxan. Justus Liebig's Ann. Chem. 123: 363-365.

Styger, G., Prior, B., and Bauer, F.F. (2011). Wine flavor and aroma. J. Ind. Microbiol. Biotechnol. 38: 1145-1159.

Sunarharum, W.B., Williams, D.J., and Smyth, H.E. (2014). Complexity of coffee flavor: A compositional and sensory perspective. Food Res. Int. 62: 315-325.

The Global Organization for EPA and DHA Omega-3s (GOED), and the Council for Responsible Nutrition. (2019). The Global Organization for EPA and DHA Omega-3s (GOED), and the Council for Responsible Nutrition. Oxidation in omega-3 oils: An overview, https://goedomega3.com/storage/app/media/scientific-reports/Oxidation\%20in\%20 Omega-3\%200ils_\%20An\%20Overview.pdf. Accessed 20 September 2019.

Tims, M.J., and Watts, B.M. (1958). Protection of cooked meats with phosphates. Food Technol. 12: 240-243.

Wang, Y., and Cui, P. (2015). Reactive carbonyl species derived from omega-3 and omega-6 fatty acids. J. Agric. Food Chem. 63: 6293-6296.

Whitfield, F.B., Mottram, D.S., Brock, S., Puckey, D.J., and Salter, L.J. (1988). Effect of phospholipid on the formation of volatile heterocyclic compounds in heated aqueous solutions of amino acids and ribose. J. Sci. Food Agric. 42: 261-272.

Wong, E., Johnson, C.B., and Nixon, L.N. (1975). The contribution of 4-methyloctanoic (hircinoic) acid to mutton and goat meat flavour. New Zeal. J. Agric. Res. 18: 261-266.

Xu, Y., Chen, Q., Lei, S., Wu, P., Fan, G., Xu, X., and Pan, S. (2011). Effects of lard on the formation of volatiles from the Maillard reaction of cysteine with xylose. J. Sci. Food Agric. 91: 2241-2246.

Yanagimoto, K., Lee, K.G., Ochi, H., and Shibamoto, T. (2002). Antioxidative activity of heterocyclic compounds found in coffee volatiles produced by Maillard reaction. J. Agric. Food Chem. 50: 5480-5484.

Yang, A., Brewster, M.J., Beilken, S.L., Lanari, M.C., Taylor, D.G., and Tume, R.K. (2002). Warmed-over flavor and lipid stability of beef: effects of prior nutrition. J. Food Sci. 67: 3309-3313.

Yang, N., Liu, C., Liu, X., Degn, T.K., Munchow, M., and Fisk, I. (2016). Determination of volatile marker compounds of common coffee roast defects. Food Chem. 211: 206-214.

Yuwanti, S., Raharjo, S., Hastuti, P., and Supriyadi, S. (2011). Inhibition of riboflavin photosensitized off flavor in milk products with $\mathrm{O} / \mathrm{W} \mathrm{mi}-$ croemulsion containing astaxanthin and $\alpha$-tocopherol. Int. Food Res. J. 18: 1375-1379.

Zamora, R., Gallardo, E., and Hidalgo, F.J. (2007). Strecker degradation of phenylalanine initiated by 2,4-decadienal or methyl 13-oxooctadeca-9,11-dienoate in model systems. J. Agric. Food Chem. 55: 13081314.

Zhang, Y., Guo, S., Liu, Z., and Chang, S.K.C. (2012). Off-flavor related volatiles in soymilk as affected by soybean variety, grinding, and heatprocessing methods. J. Agric. Food Chem. 60: 7457-7462.

Zhou, M., Robards, K., Glennie-Holmes, M., and Helliwell, S. (1999). Analysis of volatile compounds and their contribution to flavor in cereals. J. Agric. Food Chem. 47: 3941-3953. 